\title{
UMA ANÁLISE DISCURSIVA DO PROCESSO DE CONSTRUÇÃO IDENTITÁRIA DE MARIA EMÍLIA NO CONTO SENHOR DIRETOR
}

\begin{abstract}
Giselle Aparecida da Luz
Doutoranda em Estudos Linguísticos pela Universidade Federal de Minas Gerais (UFMG) gisellee.luzz@gmail.com

Danielle Cristine Fullan Doutoranda em Estudos Linguísticos pela Universidade Federal de Minas Gerais (UFMG) danifullan@gmail.com
\end{abstract}

\section{RESUMO}

O presente estudo visa analisar o conto Senhor Diretor, de Lygia Fagundes Telles (2009), com o objetivo de verificar como se dá a construção identitária da protagonista Maria Emília. Para tanto, a fundamentação teórica de nossas discussões será respaldada em Charaudeau (2009), no que se refere à identidade social e a identidade discursiva; e em Hartog (1999), em relação à retórica da alteridade. Com base em nossas análises, foi possível compreender que Maria Emília ao buscar descrever o que se passava ao seu redor acaba por narrar-se e apresentar seus valores e suas crenças para seus interlocutores.

Palavras-chave: Lygia Fagundes Telles, conto, análise do discurso, escrita feminina.

\section{RÉSUMÉ}

Cette étude vise à analyser le récit "Senhor Diretor", de Lygia Fagundes Telles (2009), pour vérifier la construction identitaire de la protagoniste Maria Emília. À cette fin, notre cadre théorique sera soutenu par Charaudeau (2009), en ce qui concerne l'identité sociale et l'identité discursive; et Hartog (1999), par rapport à la rhétorique de l'altérité. À partir de nos analyses, nous comprenons qu'en essayant de décrire ce qui se passait autour d'elle, Maria Emília finit par raconter elle-même, présentant leurs valeurs et leurs croyances à ses interlocuteurs.

Mots-clés: Lygia Fagundes Telles, récit, analyse du discours, écriture féminine. 


\section{Introdução: a década de 1970}

No presente artigo analisamos o conto "Senhor Diretor", da escritora brasileira Lygia Fagundes Telles, com o intuito de verificar como se dá a construção identitária da protagonista Maria Emília.

O conto é uma das catorze histórias que compõe o livro "Seminário dos Ratos", publicado pela primeira vez em 1977. Nele, Lygia Fagundes Telles apresenta textos que combinam o fantástico e o real, explorando conflitos existenciais e filosóficos, tais como a morte, o poder, o amor, a velhice e a loucura, sem deixar de considerar o espaço social e político.

Por isso, identificamos ao longo do conto "Senhor Diretor" diversos elementos que fazem referência ao contexto histórico da década de 1970. Tendo isso em vista, consideramos relevante destacar algumas das questões culturais, sociais e políticas presentes no conto e importantes para a compreensão de nossa análise a seguir.

A década de 1970 foi marcada por intensas transformações que, segundo Habert (2006, p. 12), definiram ao mesmo tempo o apogeu e a crise da ditadura. O Brasil ainda sofria as consequências do Al-5, com a implantação da ditadura e o fechamento total do sistema político brasileiro, que proibia, entre outras coisas, as manifestações políticas e aumentava a censura. O governo Médici segue, até 1974, marcado pelo início do milagre econômico e da intensa repressão com torturas, prisões arbitrárias e desaparecimento de militantes contrários à Ditadura Militar.

Geisel assume um país em crise em meio a uma sociedade cada vez mais insatisfeita. De um lado, a dívida externa e recessão da economia interna com os investimentos estrangeiros escassos, após a crise do petróleo em 1973. De outro, as lutas 
e mobilizações das classes operárias, artísticas e culturais aceleram a urgência de redemocratização e abertura política.

A “distensão" gradual e lenta proposta, pelo então presidente, ocorria em um período marcado, também, por profundas transformações sociais no Brasil. Os questionamentos, ainda na década de 1960, sobre as estruturas de poder, tanto de ordem política e econômica quanto social e sexual, ficam mais fortes ampliando o conflito, a luta e a reivindicação de direitos das minorias e marginalizados, como os movimentos feministas. Segundo Duarte (2003), é nesse período que ocorre no Brasil a onda mais exuberante e capaz de alterar costumes, problematizar o aborto, o controle de natalidade e o direito ao prazer.

Diante dos profundos questionamentos e tensões durante a segunda metade do século $X X$, a indefinição dos sujeitos sociais e os choques geracionais, abriu-se espaço para aquilo que Debord (1997, p. 14) chama de sociedade do espetáculo: “O espetáculo apresenta-se ao mesmo tempo como a própria sociedade, como uma parte da sociedade e como instrumento de unificação." E o instrumento de unificação é a mídia, que se vale dos meios de comunicação para abrir as portas de um novo mundo, marcado pelo consumismo.

E como a literatura de autoria feminina brasileira reagiu a tal contexto?

Duarte (2003) lembra que muitas delas aproveitaram de sua escrita para manifestar abertamente seu descontentamento com o governo, como foi o caso de Nélida Piñon. Outras, como Lygia Fagundes Telles, trouxeram algumas dessas inquietações para seus trabalhos, promovendo 'reflexões que suscitam as leitoras" (DUARTE, 2003, p. 167). 


\section{Referencial teórico}

Apoiando-nos na esteira dos estudos dialógicos de Bakhtin (2003), acreditamos que um dos caminhos possíveis para compreender a forma como as mulheres são apresentadas no conto "Senhor Diretor", de Lygia Fagundes Telles (2009), seria justamente buscar refletir sobre a relação entre identidade e alteridade na construção do sujeito psicossocial. Para tanto, propomos uma discussão que se dará em dois momentos: partiremos inicialmente dos estudos de Charaudeau (2009), a respeito da identidade social e da identidade discursiva; e, em seguida, evocaremos as contribuições de Hartog (1999), em relação à retórica da alteridade.

\subsection{Identidade social e identidade discursiva}

Por meio de um diálogo entre o campo dos estudos discursivos com os estudos da psicologia, da filosofia, bem como da sociologia, Charaudeau (2009) aponta que o processo de reflexão sobre a identidade de cada sujeito está intimamente relacionado à uma tomada de consciência sobre si mesmo, isto é, uma ponderação sobre quem ele é e o papel que ocupa no espaço em que está inserido.

Tal processo de conscientização do sujeito psicossocial sobre o lugar que ocupa, no espaço em que está inserido, está atrelado à relação que estabelece com aqueles que estão ao seu redor. A esse respeito, Charaudeau $(2009$, p. 1) ressalta:

[...] cada um dos parceiros da troca está engajado num processo recíproco (mas não simétrico) de reconhecimento do outro e de 
diferenciação para com o outro, cada um se legitimando e legitimando o outro através de uma espécie de "olhar avaliador" - o que permite dizer que a identidade se constrói através de um cruzamento de olhares : "existe o outro e existo eu, e é do outro que recebo o eu". Se tomarmos o ponto de vista da comunicação linguageira segundo E. Benveniste, não há eu sem tu, nem tu sem eu, o tu constitui o eu.

Dessa maneira, é possível notar que será mediante a existência do outro que o sujeito poderá tomar consciência de sua própria existência. Nesse sentido, o movimento de olhar o outro, e reconhecê-lo a partir de suas singularidades, possibilita que o sujeito olhe para si mesmo encontrando sua singularidade.

Será que mediante a percepção das diferenças a relação entre os sujeitos será sempre de partilha e diálogo?

Para compreendermos esse questionamento, basta olhar para a sociedade na atualidade e pensar como as pessoas reagem quando é emitido um ponto de vista diferente do delas. A esse respeito, Charaudeau (2009) afirma que é possível que o sujeito se sinta ameaçado ao lidar com algo diferente do que ele está acostumado e acabe por realizar um movimento de rejeição do que lhe é apresentado. Dessa forma, ao tomar as particularidades dos outros como uma ameaça, dá-se lugar a um julgamento negativo. $O$ estudioso ressalta que quando tal forma de julgamento se enrijece e se generaliza, dá-se lugar aos estereótipos que atuarão como uma forma de proteção contra a ameaça que a diferença do outro poderá significar.

Ao ponderar sobre o papel do discurso no processo de construção identitária, Charaudeau (2009) salienta que será justamente por meio dos atos de discurso difundidos socialmente que as identidades serão construídas. Para tanto, esse processo de construção se basearia em dois pilares identitários: na identidade social e na identidade discursiva. 
De acordo o autor, a identidade social somente terá valor caso seja validada pelo grupo social em que o sujeito estiver inserido. Do contrário, tal sujeito terá sua legitimidade questionada, tendo em vista que é justamente a identidade social que assegurará ao sujeito o "direito à fala". Ao abordar a noção de legitimidade, Charaudeau (2009) afirma que um sujeito é legitimado em sua posição social apenas quando alcança o reconhecimento apresentado pelas normas institucionais que orientam os membros do grupo em que está inserido.

O referido estudioso aponta que enquanto a identidade social está intimamente relacionada aos valores partilhados por um determinado grupo, que garante a sua legitimidade, a identidade discursiva é elaborada pelo sujeito, por meio de seus atos de linguagem. Para tal, o sujeito precisará valer-se em seu discurso das estratégias de credibilidade e de captação. Para Charaudeau (2009), se o sujeito quer ser levado a sério, ele precisa mostrar-se credível e sincero a seu interlocutor. O sujeito falante pode ora empregar uma atitude discursiva pautada na neutralidade, apagando qualquer marca de avaliação pessoal, dando, assim, um ar de testemunha imparcial para o sujeito falante; ora de distanciamento, em que a postura adotado é de um especialista racional que não se deixa atingir pela paixão; e ora de engajamento, em que o sujeito é conduzido a tomar uma posição diante de determinada situação e selecionar argumentos que demonstrarão seu posicionamento.

A identidade discursiva não é algo acabado, mas algo que estaria em constante processo de construção, como aponta Charaudeau (2009). De acordo com o referido autor, a identidade discursiva resultaria da seleção das palavras, da forma como são organizados os discursos, da manipulação dos imaginários sociodiscursivos, bem como 
das particularidades da identidade social, já que será mediante a combinação das duas identidades que o sujeito elaborará seu poder de influência.

Apoiando-nos na esteira dos estudos discursivos de Charaudeau (2009), compreendemos que a base para a consciência de nossa percepção, enquanto indivíduos, está associada à nossa percepção da existência do outro, e que este é diferente de nós. 0 estudioso denomina o processo de consciência da existência do outro como a base para o "princípio da alteridade".

Tendo em vista a íntima relação entre identidade e alteridade, discutiremos, a seguir, sobre o conceito de retórica da alteridade apresentado por Hartog (1999).

\subsection{Alteridade}

Ao invés de se debruçar na construção que o narrador traz sobre os outros em sua narrativa, Hartog (1999) propõe analisar a maneira como a narrativa dá voz aos sujeitos retratados, isto é, observar como a construção narrativa "traduz" o outro e de que maneira busca levar seu leitor a acreditar na imagem que ele constrói sobre o outro. Para o referido historiador, tal relação de "tradução" do outro traz à cena uma retórica da alteridade que atua no texto, ou seja, trata-se de um processo de agrupamento de regras por meio das quais será possível realizar a fabricação do outro.

O processo de fabricação do outro se dará mediante a junção das figuras selecionadas pelo narrador e evidenciadas em seu texto, contudo, cabe ressaltar o importante papel das marcas de enunciação deixadas na obra. A esse respeito, Hartog (1999, p. 228) afirma: 
A leitura deve, pois atentar para todas as marcas de enunciação que apresentam essas figuras e que, para o destinatário, as carregam finalmente com um peso específico de persuasão. Nas Histórias, tudo se passa, antes de tudo, entre estas quatro marcas ou estas quatro operações: eu vi, eu ouvi - mas também eu digo, eu escrevo.

Notamos que a visão e a audição aparecem como marcas que legitimam e dão ainda mais credibilidade aquilo que é dito e escrito.

Segundo o historiador, enunciar o outro implica em ressaltar a diferença entre aquele que narra e aquele que é narrado, tendo em vista que existe o mundo em que se relata algo e o mundo que se relata. Hartog (1999) aponta que tal processo de descrever uma cena implica em propor ao leitor uma espécie de legenda para o quadro, isto é, uma orientação da forma como a obra pode ser "lida".

Assim como Charaudeau assinala a possibilidade de uma atitude discursiva baseada na neutralidade para a construção da identidade discursiva, Hartog (1999, p. 269), ao refletir sobre as possíveis marcas de enunciação presentes nas obras, ressalta que:

A ausência de marcas de enunciação ou seu apagamento é, pois, uma das técnicas empregadas pelo narrador para aumentar o peso da alteridade de sua narrativa. Ele dá a impressão de transmitir ao destinatário a alteridade em "estado bruto" ou "selvagem".

O aparente apagamento do sujeito no texto e a construção das possíveis nuances de um texto neutro, na realidade, trariam à tona o uso estratégico da alteridade em seu estado primário.

\section{Análise}




\subsection{Identidade}

\subsubsection{Identidade social}

O texto apresenta dois sujeitos narradores: um em terceira pessoa, marcando a presença de Lygia Fagundes Telles; e outro em primeira pessoa, Maria Emília. Nossa leitura se concentrou em entender o processo de construção identitária de Maria Emília. Sendo assim, apresentaremos a análise da identidade social da protagonista do conto, considerando-a como um dos elementos que constituem o sujeito, conforme postula Charaudeau (2009).

Já no início do conto, Maria Emília evoca sua identidade social como aquela que precisa ser reconhecida por todos, e que vai conferir legitimidade a seu discurso: "Senhor Diretor: antes e acima de tudo quero me apresentar, professora aposentada que sou, paulista, solteira" (TELLES, 2009, p. 18 ).

Os qualitativos selecionados destacam sua posição social e contribuem para garantir o valor dos argumentos empregados por Maria Emília em seu posicionamento ao longo do texto. Uma das razões apontadas pela própria personagem, que justificaria o envio da carta, é sua crítica ao mundo de discurso vazio e cheio de imperativos da imprensa, do cinema e da propaganda, por isso ela se baseia na respeitabilidade de sua antiga profissão. Maria Emília destaca também a sua origem, pois seu discurso é dirigido a um jornal que, desde sua primeira edição, em 1966, salientava sua vocação "fundamentalmente paulista" (GABRIEL, 1986, p. 11). Além disso, o próprio fato de decidir enviar a reclamação a um jornal, deixa claro o posicionamento de Maria Emília 
contra a jovem mídia televisiva. Seu estado civil funcionaria como mais uma garantia de legitimação para outro assunto levantado em sua carta imaginária: a erotização da sociedade. Como uma mulher respeitável, ela teria assegurado o seu direito de reclamar desse mal. Mais adiante, decide manter apenas duas características de sua identidade social:

Basta isto, uma professora paulista que tomou a liberdade de the escrever porque a ninguém mais lhe ocorre expor sua revolta, mais do que revolta, seu horror diante desse espetáculo que a nossa pobre cidade nos obriga a presenciar desde o instante em que se põe o pé na rua (TELLES, 2009, p. 18).

Maria Emília acredita ter uma responsabilidade social diante desses acontecimentos, porque ela estaria do mesmo lado dos grupos detentores de uma suposta moral e ordem social: "O senhor, eu - a elite pode estar a salvo. Mas e os outros?" (TELLES, 2009, p. 21).

De modo indireto, percebe-se aqui a identificação da personagem com o regime militar e todos os apoiadores civis vinculados à Ditadura, representados a partir do emprego do sintagma "elite".

Contudo, no decorrer do conto, a personagem percebe seu deslocamento em relação ao seu papel social e o espaço onde estaria inserida. Se por um lado, o fato de ser uma sóbria aposentada pode lhe garantir alguma respeitabilidade e espaço de fala, graças também ao contexto político dominante no qual está inserida, por outro, a velhice acentua a condição de seu apagamento em uma sociedade que privilegia a juventude e a sexualidade. 


\subsubsection{Identidade discursiva}

Após nos debruçarmos sobre a constituição da identidade social de Maria Emília no conto "Senhor Diretor", propomos, a seguir, uma reflexão no que tange à sua identidade discursiva, de acordo com a discussão proposta por Charaudeau (2009).

No conto, podemos observar o entrelaçamento da identidade social da professora paulista com a identidade discursiva de Maria Emília, como aquela que se revolta e fica horrorizada "[...]diante desse espetáculo que a nossa pobre cidade nos obriga a presenciar desde o instante em que se põe o pé na rua" (TELLES, 2009, p. 17).

E qual seria tal tipo de espetáculo ao qual Maria Emília se referia?

Ao analisarmos o conto observamos que a construção da identidade discursiva de Maria Emília se dá por meio de um processo de polarização em que de um lado estaria ela e os que partilhavam de seus valores e, do outro, os sujeitos sociais que apresentariam uma forma diferente de ver a vida da qual ela havia sido criada. Teríamos então a máxima: Nós versus Eles, marcando aqui o choque geracional, e também social, do período, como apontamos no início do trabalho.

Enquanto Maria Emília prezaria pelos valores morais e da integridade, a sociedade seria apresentada como o espaço da sujeira e da imoralidade:

Mas a praça devia estar tão suja, que prazer podia se encontrar numa praça assim? Era um bom assunto para a carta, a sujeira dos nossos jardins, o único problema é que podia ficar comprida demais. E queria ser breve (TELLES, 2009, p. 20).

Não, a carta não seria sobre o lixo, nada de misturar os assuntos, a sujeira interna, Senhor Diretor, essa é pior do que o lixo atômico porque não se lava com uma simples escova (TELLES, 2009, p. 26). 
É possível notar que, embora Maria Emília expresse um profundo desejo de manter a objetividade de sua carta, evitando a menção de elementos paralelos à sua temática principal, é surpreendida por suas reflexões internas que são verbalizadas ao longo de sua narrativa. Não se trata apenas do lixo externo e dos objetos descartados pelos indivíduos, trata-se de um lixo interno que incomodava profundamente a Maria Emília.

Associada à tal polarização da sujeira interna versus limpeza interna, a protagonista adota para si uma posição de moderação, timidez, prudência e controle ao passo que apresenta as feministas como imprudentes e descontroladas: "Mas meus Céus, se ao menos fossem mais moderadas. Mais discretas. Reivindicar tanta coisa ao mesmo tempo, tanta mudança de repente não pode ser prejudicial? Um abalo nas nossas raízes, acho que estão correndo demais." (TELLES, 2009, p. 22). Maria Emília, em diversos momentos, no conto, posiciona-se em relação à postura das mulheres feministas e ressalta que temia, caso aderisse ao grupo, ficar como Mariana, que usava apenas jeans e vivia cheia de anéis. Por meio da construção da identidade discursiva de Maria Emília, podemos notar a evocação dos imaginários sociodiscursivos a respeito das feministas como sendo aquelas que não se cuidavam e que se restringiam ao clássico jeans e camiseta branca.

Duarte (2003) destaca que, apesar das conquistas, a resistência em torno da palavra feminismo permanece:

A reação desencadeada pelo antifeminismo foi tão forte e competente, que não só promoveu um desgaste semântico da palavra, como transformou a imagem da feminista em sinônimo de mulher mal amada, 
machona, feia e, a gota d'água, o oposto de 'feminina'. (DUARTE, 2003, p. 151).

Notamos que os imaginários sociodiscursivos partilhados pela personagem sobre as feministas estariam atrelados a uma visão antifeminista.

Por que será que Maria Emília temia uma mudança nos padrões sociais da época em que estava inserida?

Em diversos momentos do conto temos a evocação do lugar do medo. A protagonista aparece como aquela que temia a solidão e que nunca tivera ninguém em sua vida, diferentemente de Mariana. Observa-se a polarização das duas personagens: enquanto uma representaria a fase de seca do rio, a outra representaria a fase de abundância.

Em outro momento, notamos o medo da velhice "Tanto medo, Senhor Diretor. Tanto medo. Eu também tenho medo. É duro envelhecer, reconheço. Mas e o orgulho?" (TELLES, 2009, p. 18). Maria Emília constrói sua identidade discursiva deixando marcas no texto em relação ao seu medo de envelhecer. Observamos que a protagonista se esforça para apresentar ao Senhor Diretor uma carta pautada pelo viés da neutralidade, buscando relatar apenas o que viu, ouviu e experienciou, contudo, suas memórias surgem como um alter ego que revelam mais do que ela gostaria que fosse revelado. Dessa forma, a velhice surge, no conto, como o momento em que traria consigo a seca da solidão.

Ao olhar para Mariana e sua abertura para debater livremente sobre temas que seriam tabus em sua época, Maria Emília posiciona-se de forma explícita: “Condenei-a, sim, e com que rigor. Não seria pura inveja? Esse meu sentimento de superioridade. Desprezo. Inveja, meus Céus?" (TELLES, 2009, p. 29). A posição adotada pela protagonista 
instaura um olhar de superioridade, julgamento e condenação, ao passo que Mariana ocuparia uma posição de inferioridade e, consequentemente, o banco dos réus. Assim, constrói-se a polarização de Maria Emília e do Senhor Diretor como representantes da elite intelectual e política e a base a ser seguida; ao passo que os outros seriam tomados como o lugar da sujeira e da imoralidade.

\subsection{Alteridade}

Vimos que a construção da identidade de Maria Emília se dá a partir de um processo envolvendo as identidades social e discursiva. Apresentaremos a seguir como a personagem elabora a tradução do outro, em sua narrativa, a partir das discussões propostas por Hartog (1999).

Há em Maria Emília o desejo de apagar as marcas da enunciação ao longo de todo o conto como uma estratégia para aumentar o peso da alteridade. Sua primeira tentativa de neutralidade é retirar a palavra "solteira" da carta imaginária. Ao avançar na narrativa, ela tem mais dificuldade de elaborar um discurso isento sobre o outro, como em: "Já estava escrevendo uma outra carta, meus Céus, não misturar os assuntos que velhice era outro tópico, agora tinha que concentrar nessa sufocante vaga de vulgaridade de contaminava até as pedras" ou "Espera, melhor cortar esse pedaço, mais objetividade" (TELLES, 2009, p. 19-20).

Assim, a carta cujo objetivo era relatar o horror de uma cidade suja, sexualizada e inundada pelos imperativos comerciais, transforma-se em um desabafo: "Senhor Diretor, que esta pobre cidade - que é que tem mesmo esta pobre cidade? Acabei falando em 
outras pessoas, em mim. Espera, vamos começar de novo, sim, a carta" (TELLES, 2009, p. 31).

Maria Emília desdenha das pessoas que encontra pelo caminho, entre a banca de revistas e o cinema. A menina mascando chicletes enquanto escolhe a revista, a mulher rebolante de minissaia, a jovem prostituta, o homem descascando a tangerina e o casal no cinema são um retrato de uma sociedade aterrorizante. A única exceção é o porteiro:

Em meio da invasão dos bárbaros, ainda restavam alguns antigos habitantes da aldeia, raros, sim, completamente derrotados (a roupa do porteiro mal guardara a cor) mas conservando o sentimento do respeito ao próximo, não, não pedia amor mas ao menos respeito (TELLES, 2009, p. 28).

O detalhe da roupa desbotada da única pessoa por quem Maria Emília demonstra alguma simpatia em todo o conto é a representação de um passado que, segundo ela, estaria fadado ao desaparecimento.

Quando adentramos as memórias e devaneios da personagem, percebemos que todas são mulheres. Mariana, sua amiga, surge como a referência maior para Maria Amélia, sempre dialogando com a oposição excesso x escassez da manchete do jornal, como vimos anteriormente.

É aniversário da protagonista, mas só sabemos sua idade porque ela diz ser mais jovem que Mariana. Maria Emília lê o Jornal da Tarde, enquanto a amiga preferia os jornais populares. Audaciosa, assistiu ao "filme da manteiga" e casou-se três vezes. Podemos identificar a rigidez de Maria Emília em relação ao comportamento de Mariana quando ela descreve o momento em que a amiga lhe contou sobre um amante, a cirurgia 
plástica e as pílulas homeopáticas. Mas, ao realçar as diferenças que existiam entre as duas, ela percebeu que tamanho rigor escondia algo sobre ela mesma:

Condenei-a, sim, e com que rigor. Não seria pura inveja? Esse meu sentimento de superioridade. Desprezo. Inveja, meus Céus? Eu tinha inveja da sua vida inquieta, imprevista, rica de acontecimentos, rica de paixão - era então inveja? Olha que você pintou e bordou, eu the disse outro dia e ela riu e seu olhar ficou úmido como se ainda fosse jovem, juventude é umidade (TELLES, 2009, p. 30).

Com idades próximas, Mariana fez com que Maria Emília questionasse não apenas sua relação com a velhice ou a sujeição à sociedade de consumo. Ela desencadeou uma reflexão sobre uma vida marcada pela seca, pela rigidez e pelo controle. Falar da amiga a fez descobrir os próprios medos e conclui: "Desconfio às vezes que ela está ficando louca, que todos estamos ficando loucos" (TELLES, 2009, p. 20).

A protagonista também fala das jovens feministas e suas amigas. Podemos inclusive encontrar uma oposição entre esses dois "outros". Se as primeiras são cultas, inteligentes e de nível universitário, são suas amigas:

Eleonora, de bacia quebrada, a coitadinha. Mariana, se embaralhando em alguma mesa, a cabeça já não dava nem para um sete-e-meio e inventou de aprender bridge, não estava na moda? Beatriz, pajeando o bando de netos enquanto a nora adentrava no oitavo mês. E Elza estava morta" (TELLES, 2009, p. 27).

Solteira, Maria Emília não tinha netos para se ocupar, como as mulheres de sua idade. Se recusava a seguir modas e, ao que tudo indica, possuía boa saúde. Participar de uma mesa-redonda do grupo feminista parece revelar um interesse em conhecer o 
mundo em transformação. Esse contato entre gerações foi um encontro catalisador de profundas reflexões.

Vemos que a relação entre Maria Emília e as jovens feministas é ambígua. Ao mesmo tempo em que se simpatiza com elas, teme as consequências de suas reivindicações: "Um abalo nas nossas raízes, acho que estão correndo demais." (TELLES, 2009, p. 22).

Vale lembrar que ressaltar as diferenças aumenta a distância entre os sujeitos, por isso, identificamos novamente a presença de um choque geracional e ideológico. Maria Emília viu o seu estereótipo de prostituta abalado ao encontrar uma jovem de "perfil mimoso". Ao ouvi-la, a protagonista até tenta se esforçar para compreendê-la, sem sucesso: "Então tentei ficar solidária na cólera e descobri que estava era com raiva dela, ora que despautério! Será que não podia escolher uma outra atividade?" (TELLES, 2009, p. 23). Ainda assim, solidariza-se com a condição da mulher retratada no encontro, como a interrupção da gestação em casos extremos e os casos de mutilação feminina.

Os exemplos das mulheres falando abertamente sobre sexualidade, imediatamente, fizeram com que Maria Emília se lembrasse da mãe: “Fiquei deprimida, pensando na mamãe que não fez a tal incisão, mas que nunca sentiu o menor prazer. $E$ teve oito filhos. Oito. Quarenta anos de casamento sem prazer: um agulheiro calado." (TELLES, 2009, p. 23). Reconhecer o medo da mãe em relação ao sexo possibilita a narradora a identificar o mesmo medo em si.

O medo do outro como reflexo do próprio medo está também nos trechos em que Maria Emília fala de suas antigas alunas. Esquivava-se de qualquer contato físico com elas, apesar de reconhecer as despedidas chorosas e as flores recebidas no final do ano. Mas é com um ar pesaroso que destaca o fato de provavelmente ter sido esquecida por 
elas: “A marca ficou só em mim, nesse meu jeito de olhar as pessoas, vigilante, desconfiada. A verdade é que eu tinha medo delas como elas tinham medo de mim, mas seu medo era curto. O meu foi tão longo, Senhor Diretor. Tão longo" (TELLES, 2009, p. 24).

As traduções do outro a partir das percepções de diferenças fizeram com que Maria Emília conseguisse se redescobrir. Mulher, idosa e solteira, atravessou um tipo de sociedade patriarcal e castradora, com características bem marcadas e conhecidas. Vê-se deslocada na sociedade da década de 1970, absorvida pelas lutas e contradições de um mundo em transformação. Desamparada ao reconhecer suas referências em ruínas, é obrigada a reavaliar os valores que aprendeu, e seguiu, a partir do outro.

\section{Considerações finais}

Lygia mais uma vez se mostra hábil na tarefa de nos apresentar personagens que destacam questionamentos existenciais como o medo, a solidão, a velhice e a condição da mulher. Tais histórias são construídas sem deixar de lado os acontecimentos externos às personagens, convidando o leitor para uma viagem reflexiva sobre o estar no mundo.

Sair de casa para fugir do encontro com os sobrinhos no dia do seu aniversário serviu para que Maria Emília nos revelasse sua identidade através dos encontros e desencontros de sua vida. O trajeto real e mental também foi marcado pelas impressões do outro. As pessoas que cruzaram seu caminho e suas lembranças serviram para realçar as experiências cristalizadas que enrijeceram a protagonista. Ao completar mais um ano de vida, sente dificuldade em reconhecer seu papel e conciliá-lo com as demandas sociais. Indiretamente, o conto também dá sinais de que a ditadura militar não havia conseguido 
cumprir sua missão de mantenedora da ordem e dos bons costumes e que, à parte da elite, havia um mundo novo irrompendo as estruturas de poder, como as feministas representadas no conto.

O confronto existencial, contudo, não indica uma ação transformadora da realidade de Maria Emília. Apesar de toda a emoção dos momentos finais do conto, a história termina como começou: deixando em aberto a situação da protagonista: "As questões estão lançadas: o leitor que opte" (LUFT, 1979, p. 89 apud LAMAS, 2004, p. 100).

Como se Lygia nos desse as pistas identitárias da protagonista e, ao mesmo tempo, lançasse a pergunta: "E então, o que você acha que aconteceu?". É a literatura mais uma vez se apresentando como um universo de possibilidades.

\section{Referências}

BAKHTIN, Mikhail. Estética da criação verbal. São Paulo: Martins Fontes, 2002 [1992].

CHARAUDEAU, Patrick. Identidade social e identidade discursiva, o fundamento da competência comunicacional In: PIETROLUONGO, Márcia (Org.). O trabalho da tradução. Rio de Janeiro: Contra Capa, 2009, p. 309-326. Disponível em: <http://www.patrickcharaudeau.com/Identidade-social-e-identidade.html>. Acesso em: 5 fev. 2018.

DUARTE. Constância. Feminismo e literatura no Brasil. In: Revista Estudos Avançados. v.17, n.49. São Paulo, set./dez. 2003. p. 151-172. Disponível em: <http://dx.doi.org/10.1590/S0103-40142003000300010>. Acesso em: 20 jan. 2018. GABRIEL, Roberto Salim. Jornal da Tarde: marco na história do jornalismo brasileiro. Revista de Comunicação, Rio de Janeiro, n. 5, 1986.p. 10-12.

HABERT. Nadine. A década de 70: apogeu e crise da ditadura militar brasileira. Série Princípios. Ática: São Paulo, 2006. 
HARTOG, François. O espelho de Heródoto: ensaio sobre a representação do outro. Belo Horizonte: Editora UFMG, 1999 [1980].

LAMAS, Berenice Sica. O duplo em Lygia Fagundes Telles. Porto Alegre: Edipucrs, 2004.

LOBO, Luiza. Guia de escritoras da literatura brasileira. Rio de Janeiro: EDUERJ, 2006.

TELLES, Lygia Fagundes. Senhor Diretor. In: TELLES, Lygia Fagundes. Seminário dos ratos. São Paulo: Companhia das Letras, 2009 [1977].

Recebido em 11 de fevereiro de 2019.

Aceite em 16 de março de 2019. 